\title{
THE EFFECT OF TIDES AND RAINFALL ON THE BREEDING OF SALT MARSH MOSQUITOES
}

\author{
By P. L. Buttrick, New Haven, Conn.
}

Early in the Spring of 1912 the Civic Federation of New Haven (Connecticut) raised funds for a campaign to control the mosquito nuisance which every summer for many years has given the city a distinction second only to certain places in New Jersey.

The chief species to be controlled was the banded salt marsh mosquito (Culex sollicitans Walk.). It was hoped to secure funds enough to ditch all the salt marshes within five miles of the center of the city, but as this was not done it was thought best to use some of the funds to oil areas which could not be drained, thus temporarily keeping down the numbers of the pest.

Early in June the writer was placed in charge of this work, as well as part of the ditching operations. The following is an amplification of part of his report to the New Haven Anti-Mosquito Committee, Inc., of the Civic Federation of New Haven, and is published with its consent. Acknowledgment is due the officials of the Engineer Corps, U. S. Army, stationed at New Haven, for permission to use government tide gage readings, and for many valuable suggestions.

The life history of the salt marsh mosquito was worked out some ten years ago by the late John B. Smith and his assistants. The eggs are laid singly on the salt marsh mud and lie dormant until covered by water, either tide or rain. They then hatch in a few hours; and in from six to fifteen days, according to the temperature, the pupae transform to adults. After hovering about the marsh grass for a day or two they migrate or are blown distances and invade summer resorts, country sides, and cities, making life miserable for the inhabitants. A few return to the marsh or remain in its vicinity and start the next generation.

The marshes where the salt marsh mosquitoes breed are usually flooded at certain periods when the tides rise above the general level, as usually occurs under the new moon. These are called the perigee tides. Consequently, shortly after this period, a brood of mosquitoes is liable to emerge. At other periods when the tides are high or when the marshes are flooded by rain other broods may be produced.

In an oiling campaign a knowledge of the time of the perigee tides is of the highest importance as it gives an opportunity for making preparations for controlling the brood following it. To determine this time, if possible, more accurately than can be done by calendar, a copy of the tide tables of the United States Coast and Geodetic Sur- 
vey was obtained. These are published annually and predict for the year the time and heights of the tides for certain important harbors on the coasts of the United States. By simple calculations, the predictions can be extended to almost any point on the coast.

These predictions are obtained by methods of very great complexity which it is not necessary to discuss here. They are highly accurate as to time and reasonably so as to height. Their inaccuracies are due largely to meterological causes which can be predicted only approximately and for a short period in advance. The predictions themselves are based on variation of the astronomical phenomena which cause the tides.

The height of the maximum high tide at a given station for each day of the mosquito season may be plotted on cross section paper and a curve drawn connecting these points. If desired, a second curve may be plotted showing the height of the minimum high tides, for the two tides which occur daily seldom rise to the same height. If both high tides are plotted it will be seen that more regular curves are obtained by crossing the curves on dates when both tides rise to the same height which occurs about every fortnight. On the accompanying chart (figure 6) compare the 1912 and ' 13 prediction curves, where both tides are plotted with those for 1910 and '11, where only the maximums are given.

Such curves show a variation of nearly half the height of the highest tides, and also that there are more or less definite periods of extreme high tides followed by periods of low high tides. By plotting the phases of the moon on the same sheet, it may be seen that the periods of extreme high tides fall under the new and the full moon. These are called spring tides. The periods of low high tides fall under the moon's first and third quarter and are called neap tides. The period of highest high water is generally at the new moon and is called the perigee tide.

It should be understood that a curve of this kind does not show the daily fluctuation of the water level, only the predicted daily maximums. Curves showing the predicted daily rise and fall may easily be constructed but are of less value, since the discrepancy between the predicted and the actual height for a given day may be quite great, but when distributed over several days is reduced:

After plotting the high tide curves the next point is to determine at what height of tide a given marsh is flooded. There are three ways of obtaining this. First; by setting a tide gage at some convenient point on a stream or in the marsh. The records of this gage will establish a flood line below which the general surface of the marsh is not cov- 


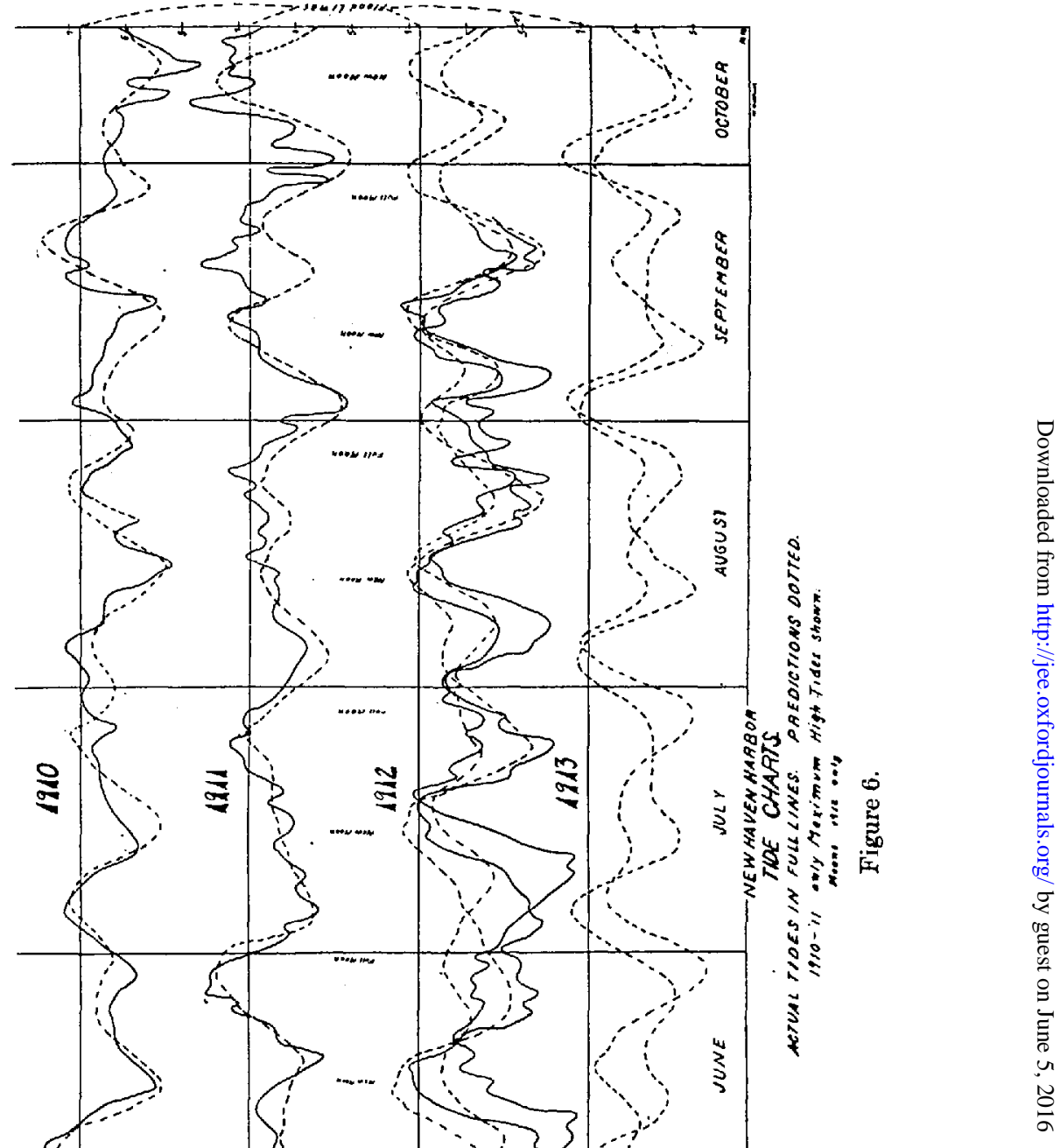


ered at high tide but above which it is. This method requires much time and is expensive but is the most accurate in the long run.

Second, to ascertain the general level of the marsh with reference to mean low water; this being the datum plane from which predictions are based. In order to do this it is necessary to use bench marks or points of known elevation with reference to sea level, and work from them. The United States Coast and Geodetic Survey, the United States Geological Survey, and the Engineer Corps, United States Army have each established bench marks along the coast which are supposed to be reckoned from mean low water, which is generally taken as mean sea level, but there may be some discrepancy and, before starting work from a given bench, it should be known that it is referred to the same datum plane as the predictions in the tide tables. Cities, towns, and railroads frequently have established bench marks which are conveniently located, but may be located with reference to high water or an assumed datum. If the correction factor is between them and the low water datum is known they may be used; otherwise, unless a line connecting them with a bench referred to mean low water is run, they are of no value.

By correspondence with the proper departments at Washington or by appealing to the proper local government officers these points can be determined. After establishing the bench mark a line of levels must be run from it to the marsh and the general level of the latter obtained within a tenth of a foot, as a tenth of a foot more or less in the height of the tide may determine whether or not a marsh will be covered sufficiently to flood the breeding pools. As entomologists are not generally also engineers it may be necessary to turn this work over to an engineer.

By adding a tenth or two of a foot to the marsh level it is possible to predict at what height of the tide it will be flooded. This for convenience may be called the flood line. The height of the flood line is not necessarily the height at which a marsh is entirely covered, simply that at which the breeding pools are filled and the grass breeding areas are flooded. In fact, at times the general level of the marsh may be scarcely covered, as the flooding of the breeding places may take place by seepage, leaving the higher parts uncovered. It may be that the height of the flood line will vary slightly from time to time according to the condition of the marsh which possibly acts as a sponge and does not always stand at precisely the same level. This matter would be a fruitful field for investigation.

The third method is to visit the marsh at high tide on different days and determine by observation at what height of tide they are flooded. 
Observations at New Haven were made by combining the second and third methods.

By drawing a line across the tide chart at a height corresponding to the height of the flood line it can be seen at a glance when flooding will take place. Working charts used in the office also had the dates marked on the horizontal ordinate and the height in tenths of feet on the vertical ordinates at the beginning of each month. The moons were also plotted. The hour of each high tide might be entered in parenthesis after the proper point on the curve which for clearness is enclosed in a small circle. By exaggerating the vertical scale the differences in the height of the tide for different days are more clearly brought out.

The levels at which different local marshes about New Haven are flooded vary. At South End a tide of 6.5 feet floods some of the lower pools. Other marshes are not flooded until it rises over 7 feet; 6.8 feet seems an average and is used in the calculations for this report. The average rise in New Haven harbor is 6.2 feet, the maximum about 8 and the minimum about 4 feet. The accompanying chart shows the relation of the tides to the flood line for various years. From them we see that occasionally the full moon tides rise above the flood line, thus starting a brood of mosquitoes. It is also evident that the perigee tides may not always rise high enough to start a brood. If every perigee and full moon tide series flooded the marshes, the 6 months from April 15 to October, - the mosquito breeding season for this locality; there would be 12,13 , or 14 broods possible, depending upon the sequence of the moons. Probably this number is never realized. The maximum number shown by the curves so far plotted is 10. This number is indicated on the 1912 curve. The minimum so far shown is 7 for the 1911 curve. Eight is probably an average, curves for 7 years only being available.

With our present knowledge of the time it takes mosquitoes to develop, we can take the first day which a marsh is flooded in a series of high tides and add the approximate number of days necessary for their development and determine within a margin of a day or so when the adults will fly.

It should be understood that temperature conditions, early or late in the season, may be such that breeding is difficult, or impossible; that heavy rains may flood the marshes at other times, producing extra broods; or that winds and other causes may depress the tides and cut out a small brood or raise them when they are near the flood line so as to produce one not scheduled.

The following shows how the August campaign was laid out on a single marsh. On Saturday, August 10, 1912, the maximum high 
tide was predicted, as will be seen from the curve, as 6.8 feet. This is sufficient to flood the West River Marshes. Development in ordinary August weather generally takes about one week; hence oiling, to be successful, must be done before the following Saturday night, or August 17. It will also be seen that the tides would continue to flood the marsh at least once daily till the end of the week so that oiling would have to be carried on with the tide still on the marsh.

Some idea of the accuracy of the predictions is obtained by comparing the predicted curves with actual tide gage readings plotted on the same sheet in the accompanying figure. Gage readings were obtained from Engineer Corps, U. S. Army, and were taken from tide gages in New Haven and Bridgeport harbors. The 1912 readings were taken from a gage in Bridgeport Harbor and correction factor figured mathematically. This probably accounts for some of the discrepancies. It will be seen that they are of sufficient accuracy to afford a reliable basis for planning an oiling campaign and if checked by gage readings from day to day would be of still greater value.

A given curve shows the periods of maximum high tides for an extended region, probably for all points within the same time belt, and would thus give a rough idea of the number of broods of mosquitoes to be expected in a given season over that territory; but for the actual heights and times of floodings a curve has only a local value. The territory over which it could be used for these purposes depending on the configuration of the coast line which determines the time and height of the tides locally. Thus, an open coast line which the tide wave strikes at right angles will have high water at approximately the same time for long stretches and it will rise to approximately the same height. On a broken coast line with bays, estuaries, fiords, etc., where the tide wave runs parallel to the shore, the time and height will vary greatly. At New Haven, where the tide wave runs parallel to the shore, a single curve only was used, but it is probable that better results would have been obtained if a separate one had been used for some of the outlying marshes. And it is certain that if the campaign had included Branford and Milford, points 10 miles east and west of New Haven harbor, respectively, that at least three curves would have been required.

The predictions are usually given for a certain point, a wharf head, breakwater, lighthouse, or the like. The salt marsh may be some miles away. If further up harbor, an addition sometimes as great as 2 hours must be made for the tide to reach that point. If down harbor, it does not necessarily follow that a deduction is required, as the resistance of the stream bed and marsh surface to the tide wave is great and even here the tide is apt to be at flood later than at the 
point where the prediction is made. These points have to be worked out locally and are of chief importance as indicating when the marsh will be uncovered during periods of high tides, as work on them is easier and more effective at that time.

Although rainfall is a factor in the abundance of mosquitoes, it does not necessarily follow that the more rain the more mosquitoes. So far as salt marsh mosquitoes are concerned, the time and size of the individual rains are of great importance. A rain storm occurring when the tides almost reach the flood line may be sufficient to raise the water level so that a brood is produced. At another period when the tide level is low the same amount of rain might be carried off without its first covering the marsh. As near as we can judge at present, it takes a rainfall of at least an inch within 24 hours to start a brood of salt marsh mosquitoes, although rain in any amount, when larvæ are growing, will help to keep the pools from drying and increase the size of the brood. Rain may at times actually prevent breeding. A slight rain may cause the eggs to hatch but not provide water enough for their full development, thus effectually destroying them.

As is seen from the tables, after the first of June the rainfall at New Haven for 1912 was below normal as well as below the precipitation for 1911.

RAINFALL AT NEW HAVEN, CONN., DURING MOSQUITO SEASON.

(From United States Weather Bureau)

\begin{tabular}{|c|c|c|c|}
\hline & NORMAL & 1911 & 1912 \\
\hline April. & 3.56 & 4.31 & 4.56 \\
\hline May.. & 3.64 & 0.74 & 0.34 \\
\hline June. . & 3.17 & 2.73 & 0.50 \\
\hline July....... & 4.78 & 2.17 & 2.14 \\
\hline August. $\ldots \ldots \ldots \ldots \ldots \ldots \ldots \ldots \ldots \ldots \ldots \ldots$ & 4.99 & 5.57 & 3.22 \\
\hline September............................ & 3.79 & 2.33 & 2.32 \\
\hline October (1st to 15 th $) \ldots \ldots \ldots \ldots \ldots \ldots \ldots \ldots$ & 1.83 & 2.12 & .11 \\
\hline
\end{tabular}

However, the rains in 1912 were largely at such times as to aggravate mosquito breeding. Starting with April, there were heavy rains about the 29th which increased the size of the second brood of the season. On May 16, at the height of the perigee of that month, it rained 2.85 inches. During June, not enough rain fell at any one time to affect breeding conditions. On July 21, just as the last of the July brood was emerging, we had nearly an inch of rain, which served to provide enough water to allow the fag end of the brood to 
escape where oil had not been applied. From August 10 to 25, during the August perigee, 2.85 inches of rain fell, an amount ample to provide a brood on its own account. At the time of the first September brood it rained in all 0.95 of an inch, enough to materially increase the size of that brood. All in all, rain-fall conditions in 1912 decidedly favored an abundance of salt marsh mosquitoes about New Haven.

Investigations along the line of the relations of the tides and rainfall to breeding of salt marsh mosquitoes are far from complete, and offer an interesting opportunity for the investigator looking for a chance to increase our knowledge of the obscure physical causes which influence the varying abundance of life on our planet. Such an investigation would in the end pass out of the field of the entomologist into that of the engineer, or physiographer and the geologist, according as stress was laid on the tides or the marshes, but there is room for much more investigation on the purely entomological side.

\section{NOTE ON THE FLOWERING AND FRUITBEARING OF YUCCA ALOIFOLIA IN SOUTH AUSTRALIA}

By J. G. O. Tepper, Norwood, South Australia

Twenty years ago the writer contributed a short note to Insect Life, 1892 (Vol. IV, p. 74), when he first observed sound, but then still immature fruit at a distance from Adelaide of 30 miles; this struck me as singular on account of its dependence upon a highly specialized moth, endemic as well, in the American home. Excess of office work prevented me from investigating the problem personally as to the pollination of the Yucca in this state, there being no plants accessible to me, and the few other South Australian lepidopterologists were probably in a like fix, for nothing so far seems to have been done to discover the insect agent. However, a year or two later I acquired a young shoot of the fruiting species of Yucca, and planted it in my own back garden, where it prospered and grew, but did not flower for many years.

Three years ago, however, when the tree had attained a height over eight feet, it developed its virginal flower spike, but this set no fruit. Last year (1911), however, it produced two opposite branches near the crown, and both of these developed flower spikes, one a month in advance of the other. Of these, while the earlier one was in flower, but still bore buds, and the later only immature buds, I managed to take a photograph (Pl. 8, Fig. 1); December 22, 1911, of the crown with some difficulty. The older spike (right side) remained sterile, although 